\title{
Analysis Of Land Use In The Southern Part Of Bali Using Fusion Techniques
}

\author{
I Kadek Adiana Putra ${ }^{a *}$, Takahiro Osawa ${ }^{b}$, Made Sudiana Mahendra ${ }^{c}$ \\ a Graduate Study of Environmental Sciences, Udayana University, Denpasar, Bali 80232, Indonesia \\ ${ }^{b}$ Graduate School of Science and Engineering, Yamaguchi University, Ube Shi Tokiwadai 2-16-1, 7550092, Japan \\ c Center for Remote Sensing and Ocean Sciences (CReSOS), Udayana University, PB Sudirman Street, Denpasar, \\ Bali 80232, Indonesia \\ * Correspondence: putraadiana@ymail.com
}

Received: 12 Maret 2018; Accepted: 30 November 2018; Available online: 1 Desember 2018

\begin{abstract}
The southern part of Bali is a central region of tourism, especially in the Sub District of North Kuta, Kuta and South Kuta. The rapid development of tourism is with increasing infrastructure development. Monitor and analyze need to the land use. In this study a fusion technique with HSV method as the combination with ALOS AVNIR-2 2008 and ALOS PRISM in 2008, to estimate of the level of accuracy of image fusion with ALOS AVNIR-2 and subsequent for the analysis of land use in southern part of Bali. Results of the accuracy test with Google Earth showed land use result fusion has high accuracy with overall accuracy of $83.5 \%$. Analyze of land use showed that significant decrease of moor area in Jimbaran hill, due to rapid development of infrastructure of tourism is very rapid and then extensive residential areas have increased particularly in Sub district of the North Kuta.
\end{abstract}

Keywords: fusion techniques with HSV method; ALOS AVNIR-2 and PRISM; land use

\section{Introduction}

The ALOS utilization of data (PRISM, AVNIR-2 and PALSAR) or remote sensing data of the other, which is oriented on the availability of data and the needs of the type of information, factors that into consideration to implement cases mapping application or planning or development areas of natural resource management (agriculture, farming, geology, urban, etc.), disaster management, environmental monitoring, and so forth with the effective and efficient results is as follows: (1) the selection of data pertaining to the selection of channel/resolution or a combination of spectral channel and resolution spatial. Temporal resolution and radiometric resolution well as coverage broad of the image units. (2) Determination procedures or techniques and methods of processing and analysis of image data (ALOS, 2007).

Utilization of the image are complementary (fusion remote sensing multisensory data) can improve the accuracy of the information obtained. Such as optical data fusion and radar, can improve the accuracy of the information obtained, especially in areas that the majority of the coverage area of the image of cloud cover. Image data fusion panchromatic (black and white images) that have a high spatial resolution multispectral image data (colour images) with low spatial resolution, will sharpen or improve the accuracy of the information obtained (Pan Sharpening image technique) (Aithal and Kumar, 2009).

Population growth is very high in southern Bali from other Bali regions, such as districts of Badung. Badung Regency is one of the districts that have a wide area in between the districts in the Province of Bali this is 41852 ha with a population density reaches 1293.37 people/km2 (Central Bureau of Statistics of Badung Regency, 2009). 
Southern part of Bali also have a high income especially tourism sector (Nuarsa et al., 2018). The development of tourism in southern part of Bali, particularly in South Kuta, Middle of Kuta, North Kuta Sub-districts and make this region a world tourist destination location. As a tourist destination southern part of Bali provided several means of supporting tourism that many established on the land productive or unproductive land so that this incident raises many land use changes in the southern part of Bali (As-syakur, 2011).

General land use classification using one image. Use of one ordinary color image resulted classification with lower accuracy. To obtain classification results with high the accuracy must use high-resolution imagery. The use of fusion techniques will produce image colors and have a high resolution, because the merger fusion technique of multispectral and panchromatic imagery to produce one image is in color and have a high resolution. With a higher resolution so it is easier to do the classification and are expected to have higher accuracy. So that in this study will to do analyzes from the image fusion techniques for classification of land use in the area southern Bali especially north of Kuta, Middle of Kuta and south of Kuta Sub-district.

\section{Research Methods}

This study is located in the North of Kuta sub-district, Middle of Kuta sub-district, and South of Kuta sub-district which belongs to Badung Regency, Bali. This research employed correlation methods. The primary data which was taken from 2008 showed Table 1.

Table 1. Resource Data Analysis

\begin{tabular}{lllll}
\hline Data & Year & Source & Resolution & Temporal \\
\hline ALOS/ AVNIR-2 & 2008 & JAXA & $10 \mathrm{~m}$ & 46 day \\
ALOS/ PRISM & 2008 & JAXA & $2,5 \mathrm{~m}$ & 46 day \\
\hline
\end{tabular}

This method is used to identifying the new image from fusion technique with results of the analysis of land use.

Secondary data were obtained from Google Earth, which is then used as an indicator to analyze the level of accuracy of the image fusion results.

In this study that used of multispectral data is ALOS AVNIR-2, while the panchromatic is ALOS PRISM imagery 2008. Both of these images are combined using the HSV pansharpening method. This method will to produce multispectral images with a resolution panchromatic, the fusion algorithm that showed in Figure 1.

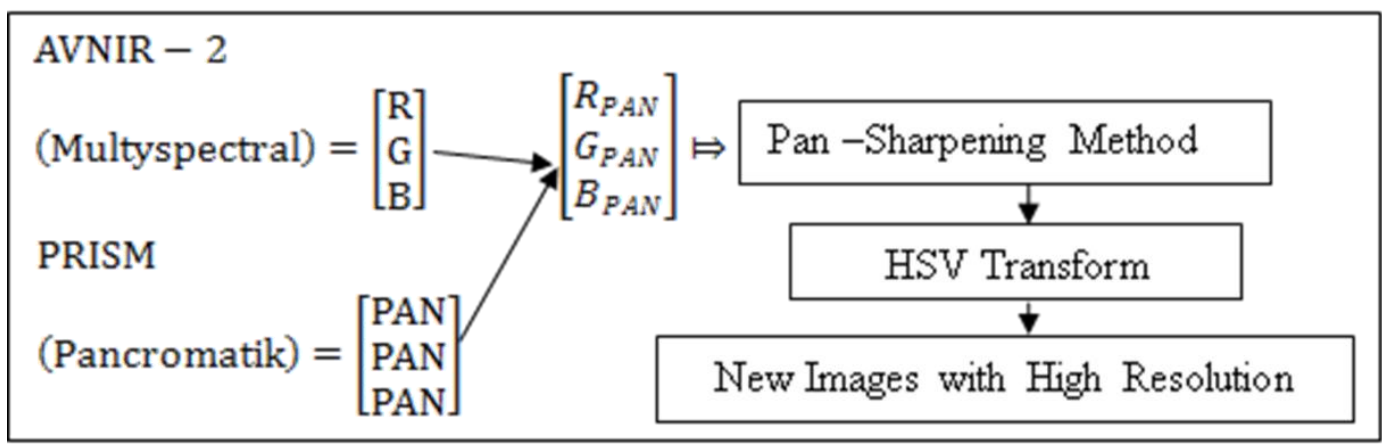

Figure 1. General of Fusion Algorithm

Classification used from both data (Fusion data) and (AVNIR-2) is the classification on screen (visual interpretation), the results then compared with Google Earth data to determine the level of accuracy of the results fusion image. If the object in both data contained similarity $\geq 80 \%$ then the level accuracy from the analysis of land use is very high so feasible to use as a land use map of the southern part of Bali area. For more details of data analysis techniques in this study show in the Figure 2. 


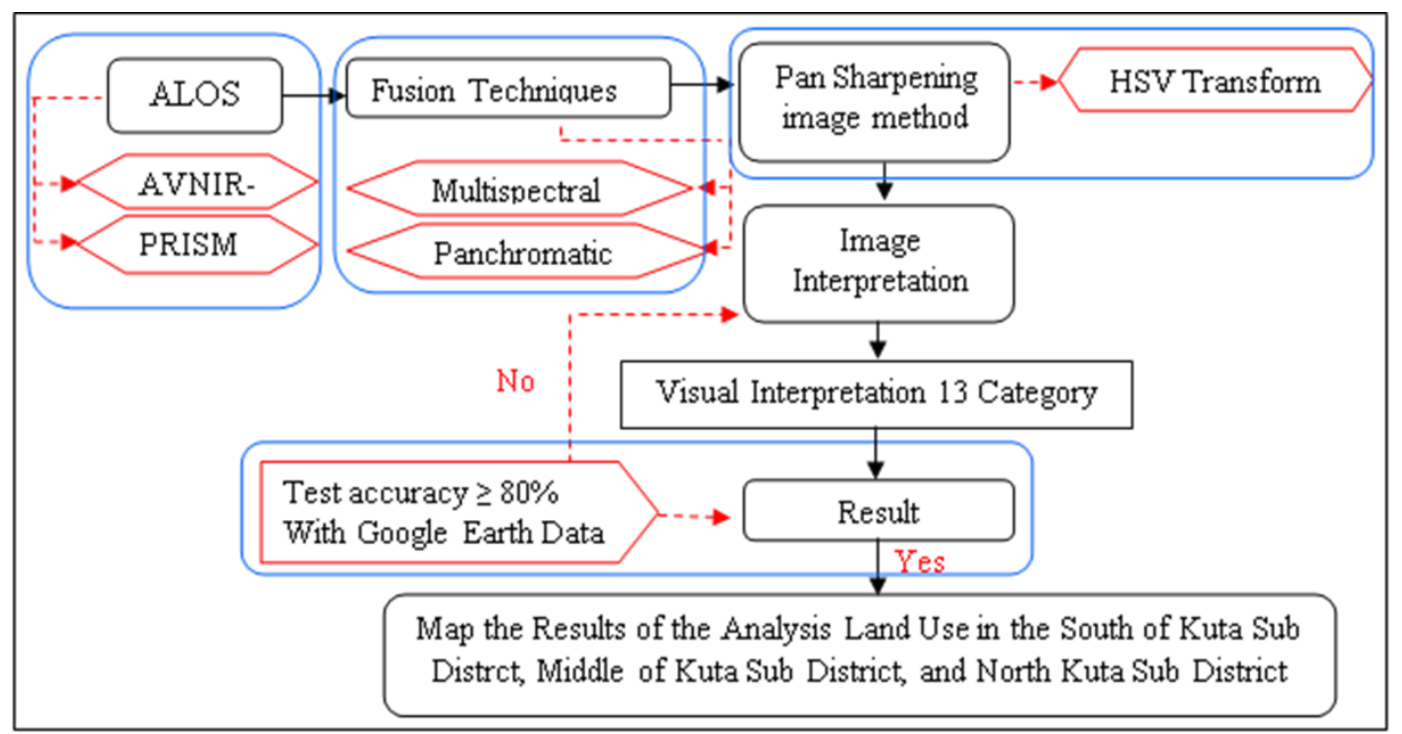

Figure 2. Details of Data Analysis Techniques

\section{Results and Discussion}

Fusion techniques performed by using HSV to obtain color images with high resolution for analysis of land use on the southern part of Bali.

\subsection{Fusion With HSV Method}

The used of fusion techniques with HSV method from ALOS AVNIR-2 with PRISM that showed on Figure 3 to 6.

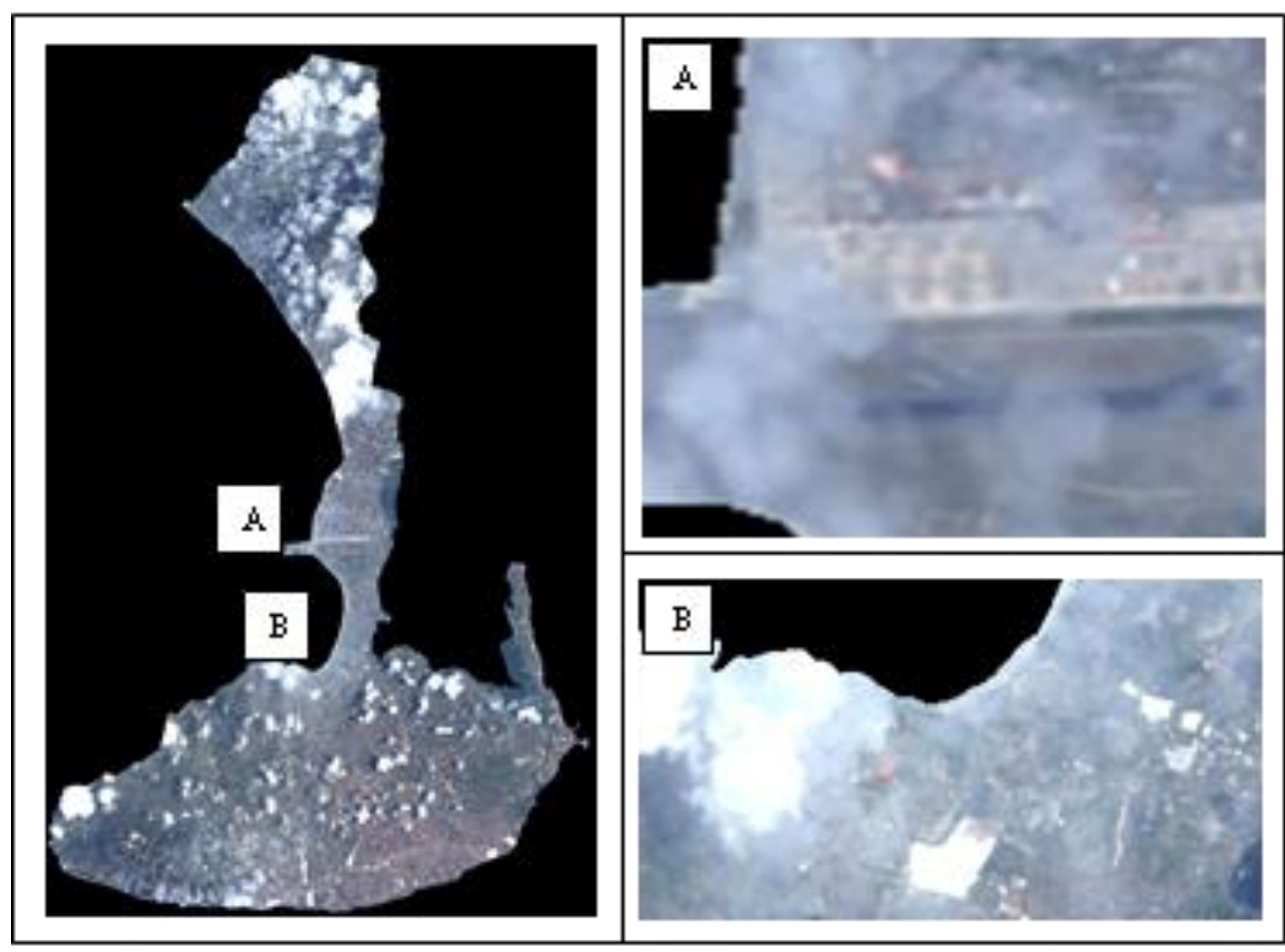

Figure 3. ALOS AVNIR-2 Image Band 3,2,1 (JAXA, 2008).

Figure 3 is a composite image AVNIR ALOS-2 acquisition in 2008 with the band 3,2,1, can show the original color of the object study. 


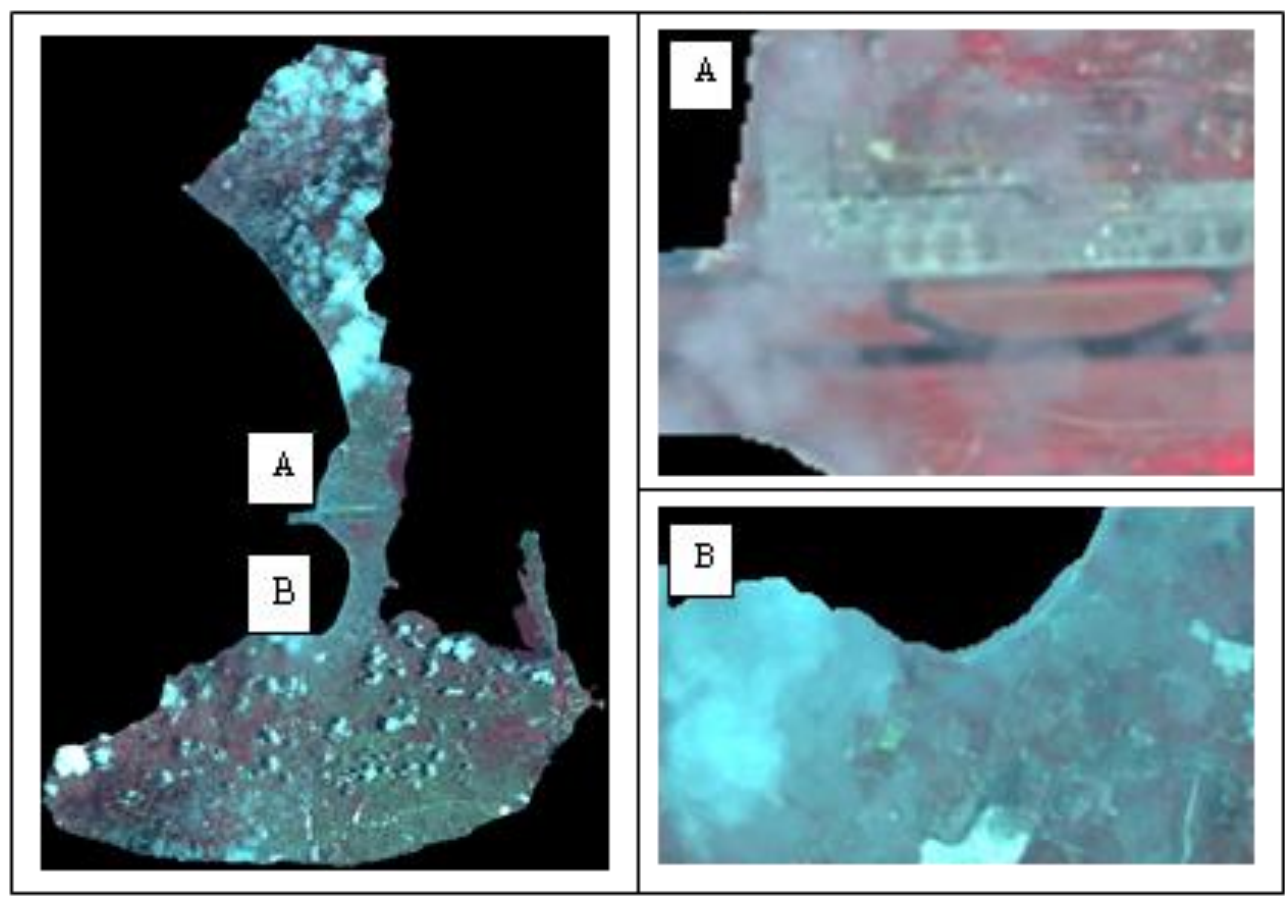

Figure 4. ALOS AVNIR-2 Image Band 4,3,2 (JAXA, 2008).

Figure 4 shows a composite image AVNIR ALOS-2 acquisition in 2008 with the band $4,3,2$ to accentuate the appearance of vegetation on the object study.
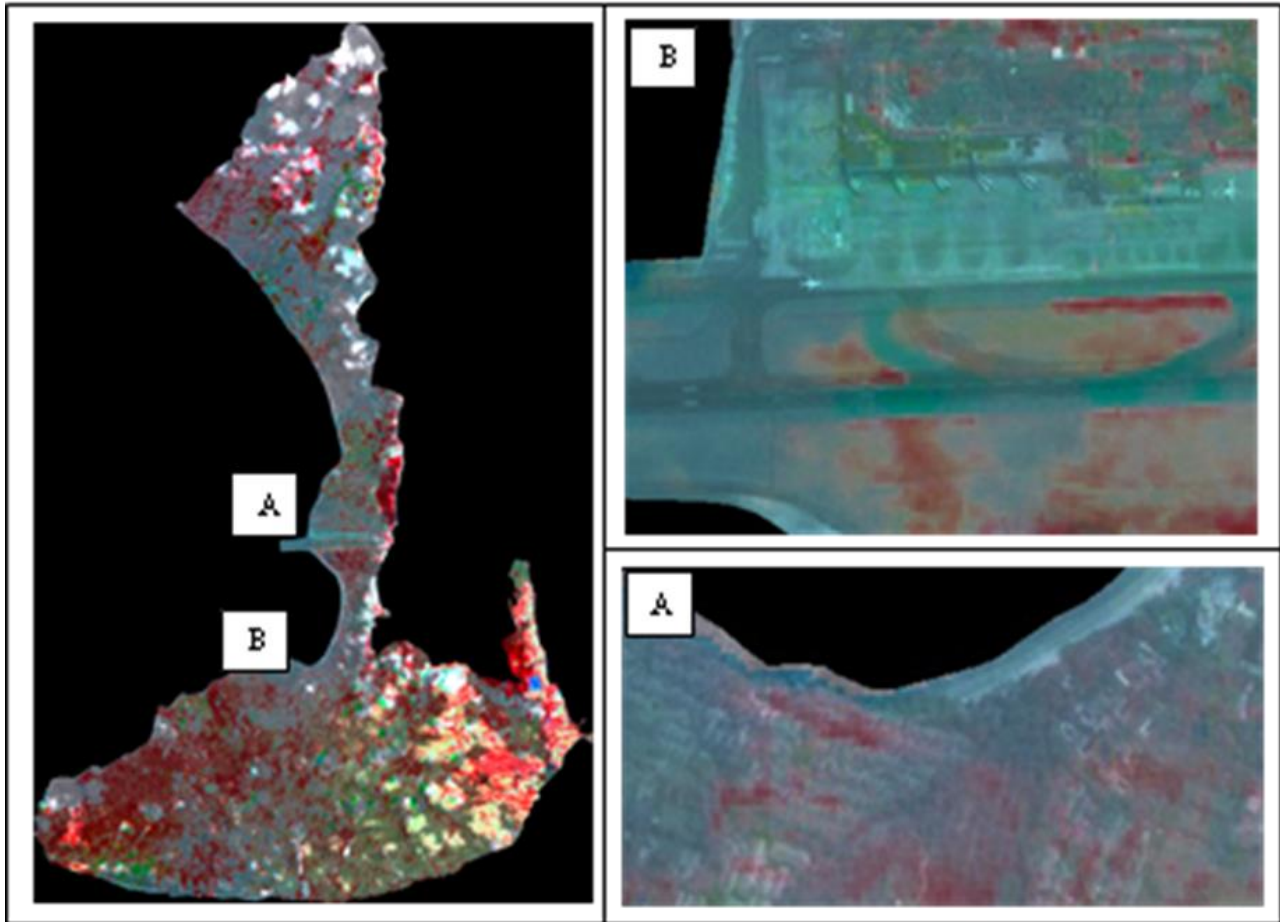

Figure 5. Image Fusion With HSV Method Band 4,3,2 Using HSV Method

The image fusion with HSV method sourced from ALOS Composite image AVNIR-2 with Band 4,3,2, image acquisition in 2008 with PRISM on the southern part of Bali produce color with the same sharpness to the image of PRISM. 


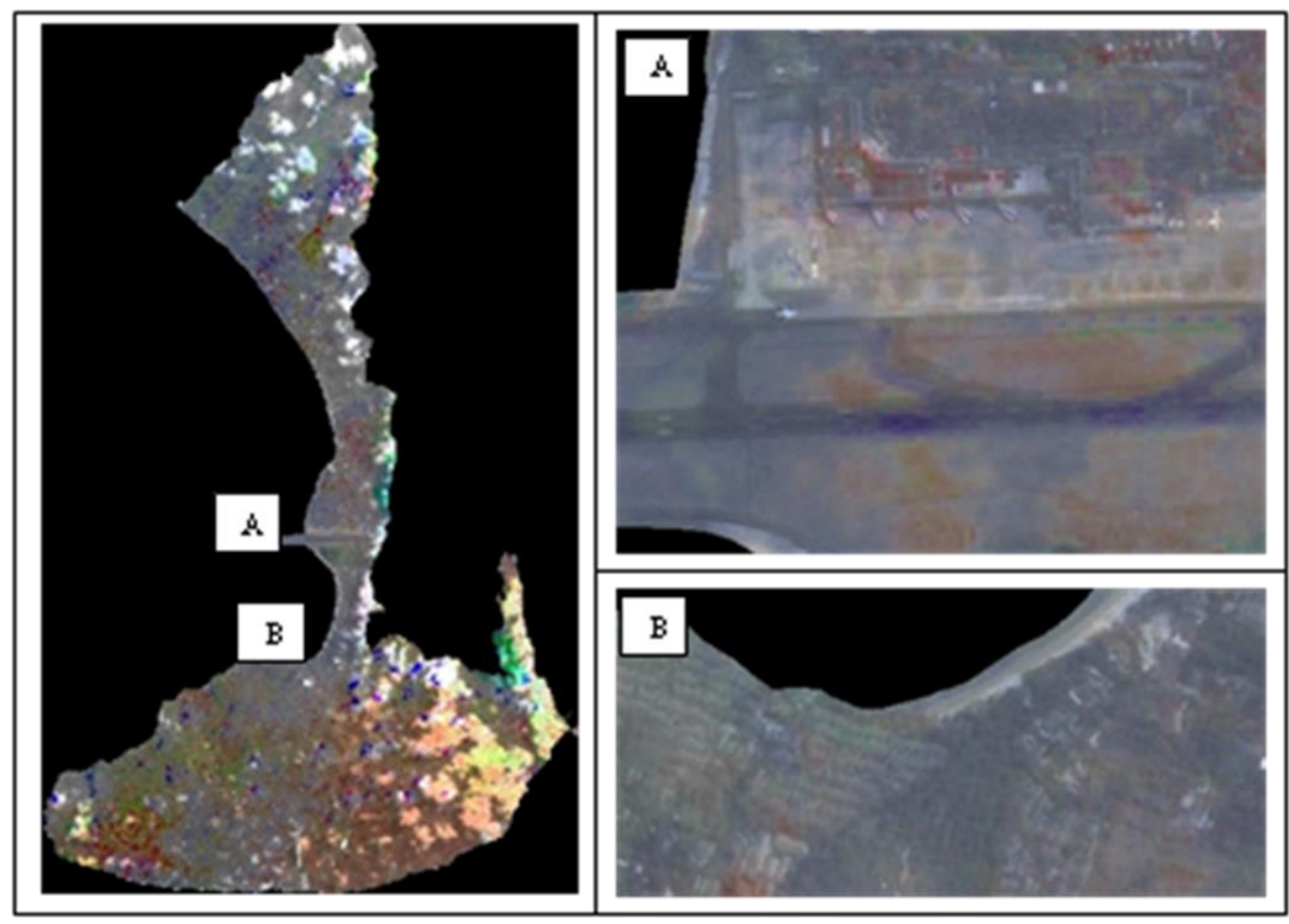

Figure 6. Image Fusion With HSV Method Band 3,2,1 Using HSV Method

Fusion techniques with HSV method is capable of producing images with high color sharpness composite $3,2,1$ and $4,3,2$. In general, image fusion can easily recognize objects, making it easier to land classify.

\subsection{Analysis of Accuracy Image Fusion and ALOS AVNIR-2}

By using $2.5 \mathrm{~m}$ resolution, image fusion of the object of study has pixel raster about 3000 pixel. It is chosen $10 \%$ of the pixel as random sampling such as 297 point samples which will be converted from vector to the raster.

a) Analysis of Accuracy Image Fusion

Result classification, Image fusion that has classifies 16 classes of land use and that classification can determine class of land use clearly and exactly. From 297 random sampling, not all of the categories of land use can be counted. There were 3 categories outside of the sample so that it was only 13 categories. Meanwhile 3 categories outside of the sample are fishpond, river, and sand. On the Analysis of the accuracy of image fusion with HSV and ALOS AVNIR-2 was conducted by comparing it with the data sourced Google Earth. The result of analysis of the accuracy of the image fusion can be shown in the Table 2.

Table 2. Legend of Land Use

\begin{tabular}{cccc}
\hline ID & Classification & ID & Classification \\
\hline 1 & Blank land & 8 & Mangrove \\
2 & Building & 9 & Moor \\
3 & Bush & 10 & Road \\
4 & Cloud & 11 & Sand Beach \\
5 & Garden/ Plantation & 12 & Settlement \\
6 & Grass & 13 & Water \\
7 & Irrigated rice & & \\
\hline
\end{tabular}


Table 3. Error Matrix: Reference Data in Columns, Classification Data in Rows

\begin{tabular}{ccccccccccccccc}
\hline ID & 1 & 2 & 3 & 4 & 5 & 6 & 7 & 8 & 9 & 10 & 11 & 12 & 13 & SUM \\
\hline 1 & 3 & 0 & 0 & 0 & 0 & 0 & 0 & 0 & 0 & 0 & 0 & 0 & 0 & 3 \\
2 & 0 & 2 & 0 & 0 & 0 & 0 & 0 & 0 & 0 & 0 & 0 & 0 & 0 & 2 \\
3 & 0 & 0 & 5 & 0 & 0 & 0 & 0 & 0 & 0 & 0 & 0 & 0 & 0 & 5 \\
4 & 0 & 0 & 0 & 0 & 1 & 0 & 0 & 0 & 0 & 0 & 0 & 0 & 0 & 1 \\
5 & 0 & 1 & 0 & 0 & 30 & 0 & 0 & 0 & 6 & 0 & 0 & 0 & 0 & 37 \\
6 & 0 & 0 & 0 & 0 & 0 & 6 & 0 & 0 & 0 & 0 & 0 & 0 & 0 & 6 \\
7 & 0 & 0 & 0 & 0 & 0 & 0 & 31 & 0 & 0 & 0 & 0 & 4 & 0 & 35 \\
8 & 0 & 0 & 0 & 0 & 0 & 0 & 0 & 2 & 0 & 0 & 0 & 0 & 0 & 2 \\
9 & 2 & 1 & 3 & 0 & 0 & 0 & 0 & 0 & 100 & 1 & 1 & 4 & 0 & 112 \\
10 & 0 & 0 & 0 & 0 & 0 & 0 & 0 & 0 & 0 & 3 & 0 & 1 & 0 & 4 \\
11 & 0 & 0 & 0 & 0 & 0 & 0 & 0 & 0 & 0 & 0 & 3 & 0 & 0 & 3 \\
12 & 0 & 1 & 3 & 0 & 4 & 0 & 5 & 0 & 9 & 1 & 0 & 63 & 0 & 86 \\
13 & 0 & 0 & 0 & 0 & 0 & 0 & 0 & 0 & 1 & 0 & 0 & 0 & 0 & 1 \\
SUM & 5 & 5 & 11 & 0 & 35 & 6 & 36 & 2 & 116 & 5 & 4 & 72 & 0 & 297 \\
\hline
\end{tabular}

Overall Accuracy: $(248 / 297)=0.835016835=83.5 \%$

Overall Misclassification Rate: $(49 / 297)=0.164983165=16.5 \%$

The result of accuracy testing by using kappa analysis with confusion matrix showed the accuracy of image fusion was $83.5 \%$ and Misclassification rate was $16.5 \%$. The amount of misclassification was caused by the amount of cloud cover found in some sample points. Besides, base on the comparison of image fusion classification with google earth showed that there were classes of land use which was not in accordance with the data from goolgle earth such as water. It will influence the increasing of misclassification from the accuracy analysis. However, the accuracy was $83.5 \%$ based on KHAT can be categorized as strong agreement.

b) Analysis of Accuracy ALOS AVNIR-2

ALOS AVNIR-2 can identify until 14 categories of land use. The location and the distribution of sample point was equivalent with the sample point from data fusion that was 297 sample points. From the distribution, it was only 12 categories which were accumulated in land use sample and 2 categories were fishpond and sand beach. Those were located outside of the sample so that kappa analysis did not read 2 categories. The legend results accuracy of the AVNIR-2 show in Table 4.

Table 4. Legend of Land Use ALOS AVNIR-2 Data

\begin{tabular}{cccc}
\hline ID & CLASIFICATION & ID & CLASIFICATION \\
\hline 1 & Blank Land & 7 & Irrigated rice \\
2 & Building & 8 & Mangrove \\
3 & Bush & 9 & Moor/ Field \\
4 & Cloud & 10 & Sand \\
5 & Garden/Plantation & 11 & Settlement \\
6 & Grass & 12 & Water \\
\hline
\end{tabular}


Table 5. Error Matrix ALOS AVNIR-2 Data: Reference Data in Columns, Classification Data in Rows

\begin{tabular}{|c|c|c|c|c|c|c|c|c|c|c|c|c|c|}
\hline ID & 1 & 2 & 3 & 4 & 5 & 6 & 7 & 8 & 9 & 10 & 11 & 12 & $\overline{\text { SUM }}$ \\
\hline 1 & 0 & 0 & 0 & 0 & 0 & 0 & 0 & 0 & 1 & 0 & 0 & 0 & 1 \\
\hline 2 & 0 & 1 & 0 & 0 & 0 & 0 & 0 & 0 & 0 & 0 & 0 & 0 & 1 \\
\hline 3 & 0 & 0 & 1 & 0 & 0 & 0 & 0 & 0 & 0 & 0 & 0 & 0 & 1 \\
\hline 4 & 1 & 0 & 1 & 0 & 6 & 0 & 16 & 0 & 6 & 0 & 13 & 0 & 43 \\
\hline 5 & 0 & 1 & 0 & 0 & 19 & 0 & 0 & 0 & 15 & 0 & 0 & 0 & 35 \\
\hline 6 & 0 & 0 & 0 & 0 & 0 & 7 & 0 & 0 & 0 & 0 & 0 & 0 & 7 \\
\hline 7 & 0 & 0 & 0 & 0 & 0 & 0 & 14 & 2 & 0 & 0 & 1 & 0 & 15 \\
\hline 8 & 0 & 0 & 0 & 0 & 0 & 0 & 0 & 1 & 0 & 0 & 0 & 0 & 2 \\
\hline 9 & 5 & 1 & 0 & 0 & 0 & 0 & 0 & 0 & 106 & 1 & 3 & 0 & 117 \\
\hline 10 & 0 & 0 & 0 & 0 & 0 & 0 & 0 & 0 & 0 & 2 & 0 & 0 & 2 \\
\hline 11 & 0 & 2 & 1 & 0 & 14 & 0 & 5 & 0 & 10 & 0 & 40 & 0 & 72 \\
\hline 12 & 0 & 0 & 1 & 0 & 0 & 0 & 0 & 0 & 0 & 0 & 0 & 0 & 1 \\
\hline SUM & 6 & 5 & 4 & 0 & 39 & 7 & 35 & 3 & 138 & 3 & 57 & 0 & 297 \\
\hline
\end{tabular}

Overall Accuracy $:(192 / 297)=0.646464646=64.64 \%$

Overall Misclassification Rate $:(105 / 297)=0.353535354=35.35 \%$

The result of kappa analysis showed that accuracy level was about $64.64 \%$ and overall misclassification was about $35.35 \%$. Based on KHT standard value, low accuracy level was caused by the area of cloud cover which reach $14.22 \%$ from the total area and spatial resolution ALOS AVNIR-2 was $10 \mathrm{~m}$ which belong to moderate resolution. For the details comparison between image fusion and ALOS AVNIR-2 can be seen on Table 6 .

Table 6. Results Analysis Between Image Fusion With ALOS AVNIR-2

\begin{tabular}{lccc}
\hline Image & ORIGINAL & ACCURACY & KAPPA \\
\hline FUSION & 16 & & \\
(Compilation) & 13 & 13 & $83,5 \%$ \\
AVNIR-2 & 14 & & \\
(Compilation) & 12 & 12 & $64,64 \%$ \\
\hline
\end{tabular}

\subsection{Analysis of Land Use in the Southern Part of Bali}

The result of land use analysis visually could show some land use classes, meanwhile source of data from fusion technique could show detail classification and more categories. In land use category, the main important was moor/ field, settlement, and irrigated rice. Except from the data ALOS AVNIR-2, there was one class which was important rather than data from fusion technique such as cloud class can be showed in Figure 7. 


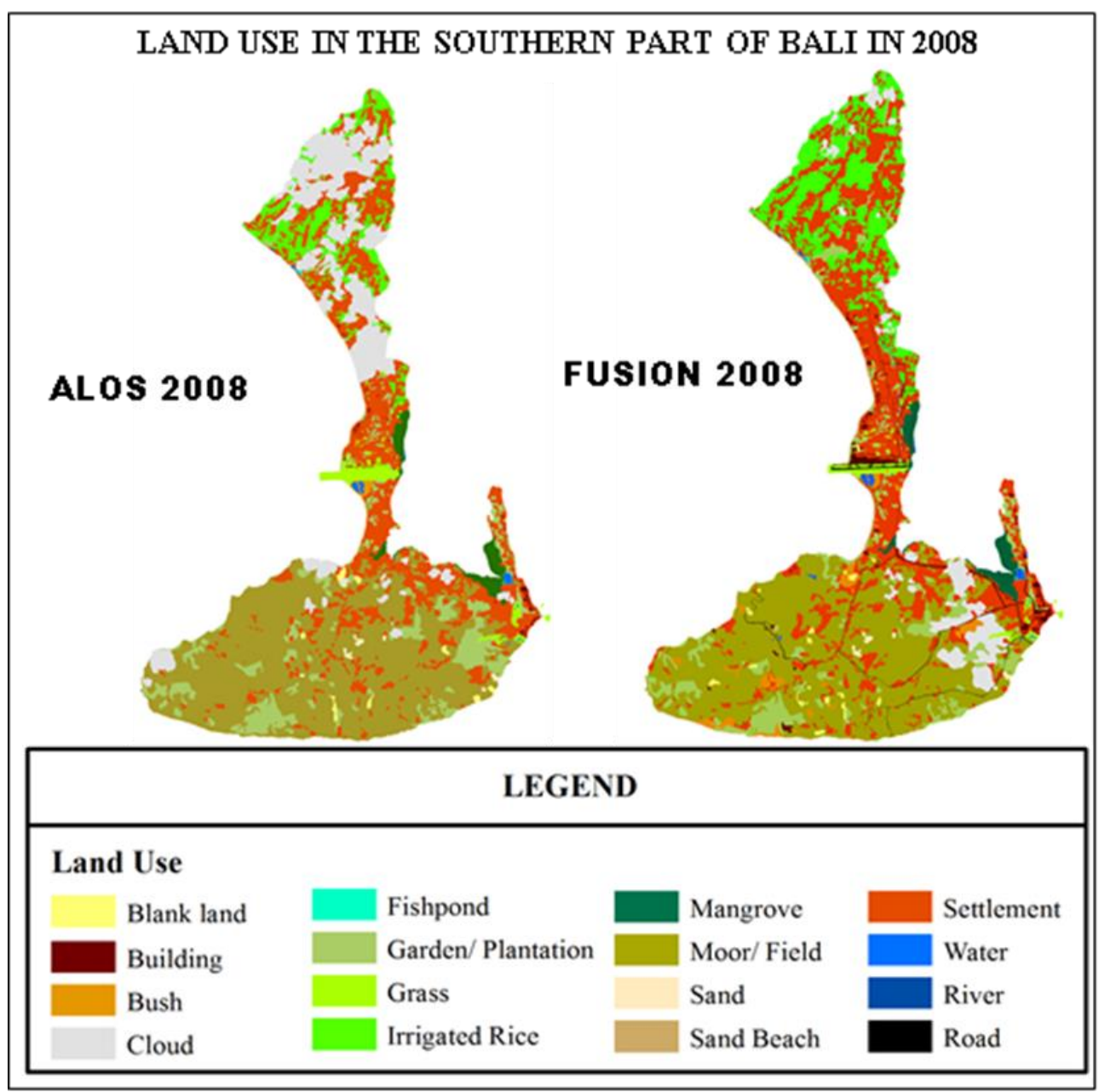

Figure 7. Comparison between ALOS AVNIR-2 2008 and Fusion 2008

Table 7. Classification Wide Area Land of Use between AVNIR-2 and Image Fusion 2008

\begin{tabular}{cccc}
\hline & Land Use 2008 & Fusion & AVNIR-2 \\
\hline 1 & Blank land & 78.808 & 69.459 \\
2 & Building & 178.453 & 55.454 \\
3 & Bush & 272.565 & 32.369 \\
4 & Cloud & 806.997 & 2153.705 \\
5 & Fishpond & 3.198 & 2.636 \\
6 & Garden/ Plantation & 1328.226 & 1438.987 \\
7 & Grass & 195.447 & 296.916 \\
8 & Irrigated Rice & 1830.871 & 945.703 \\
9 & Mangrove & 290.478 & 285.943 \\
10 & Moor/ Field & 5616.772 & 6115.991 \\
11 & Sand & 39.6 & 119.591 \\
12 & Sand Beach & 105.052 & 0.027 \\
13 & Settlement & 4176.385 & 3578.592 \\
14 & Water & 51.453 & 43.395 \\
15 & River & 7.701 & \\
16 & Road & 156.762 & \\
& TOTAL & 15138.778 & 15138.778 \\
\hline
\end{tabular}


The difference resolution which was very high between $10 \mathrm{~m}$ and $2.5 \mathrm{~m}$ produce the area of land use which is difference from fusion resolution. It can identify river, road which could not be identified previously by data ALOS AVNIR-2 with $10 \mathrm{~m}$ resolution. The difference of land use area and the amount of category can be seen on the Table 7 and Figure 8.

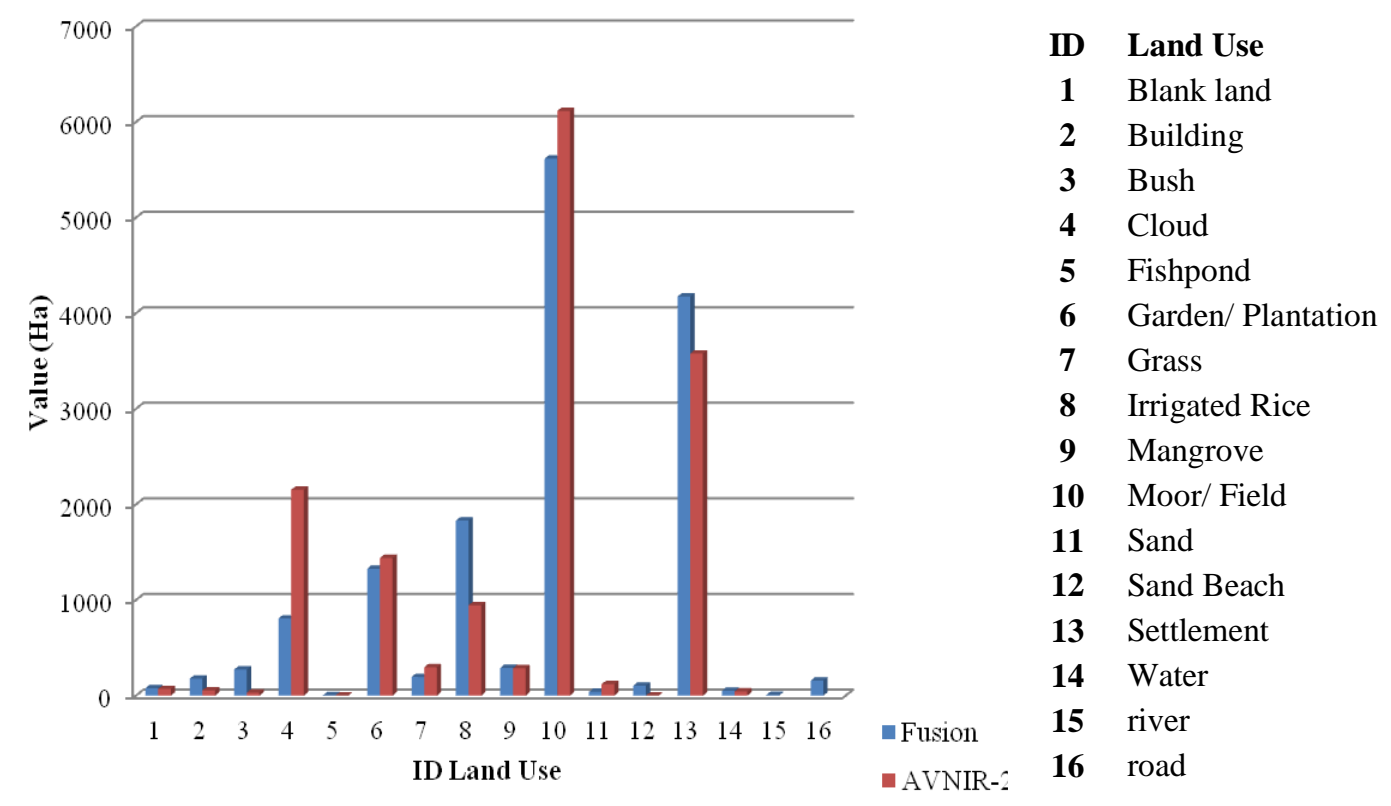

Figure 8. Land Use in the Southern part of Bali 2008

The results accuracy that show the accuracy of image fusion (method pan sharpening HSV) with a spatial resolution of $2.5 \mathrm{~m}$ have a higher accuracy rate is $83.5 \%: 64.64 \%$ and $16.5 \%$ overall misclassification: $35.35 \%$. With the accuracy of image fusion can be used as a basis for the analysis of land use. Problems were found in the analysis of this accuracy is the amount of cloud cover is very high, especially in the data AVNIR ALOS-2, thereby reducing the level of accuracy in the image. In the analysis of land use is preferred on an object that is statist and dynamic objects so they can be known patterns of development at a later stage.

Spatial distribution of land use on the southern part of Bali that know, on the North of Kuta Sub-District is more dominant dynamic land use (irrigated rice, plantation) rather than static land use (settlement and building) especially in the area Dalung, Tibu Beneng, and Kerobokan. On the Middle area Kuta Sub-district is more dominant static land use (settlement, building, and road) rather than dynamic land use especially on the area of Kedonganan, Seminyak, Legian because this area become central tourism on Badung Regency. The South of Kuta Sub-District is more dominant dynamic (moor, bush, plantation) land use (moor, bush, plantation) rather than static land use especially on the Jimbaran hill.

\section{Conclusion and Suggestion}

\subsection{Conclusion}

The result could be concluded as follows:

1. Image fusion with HSV pan sharpening method showed a capability of producing of a new high resolution image $(2.5 \mathrm{~m})$, the accuracy of the test showed about $83.5 \%(13$ classes).

2. Distribution of land use vary, for land cover in the form of static objects are more concentrated in North Kuta and South Kuta Sub District, meanwhile for the dynamic nature of land cover more was concentrated in the Kuta Sub District. 


\subsection{Suggestion}

1. The limited access in obtaining high resolution image data is very influential on multitemporary analysis especially on urban spatial arrangement analysis. Fusion technique can be used as an alternative to obtain a sharp image. Therefore, the analysis for urban areas can be done.

2. With high level of accuracy, fusion technique can be used for data analysis with efficient cost.

\section{References}

Aithal, B. H., Kumar, U., \& Ramachandra, T. V. (2009). Fusion of multi resolution remote sensing data for urban sprawl analysis. COSMAR 09, Indian Institute of Science.

ALOS. (2007). Daichi - Advanced Land Observing Satellite. [online] Japan Aerospace Exploration Agency. (http://www.eorc.jaxa.jp/ALOS/en/about/avnir2.htm.), [Cited 13 February 2013].

As-syakur, A. R. (2011). Perubahan penggunaan lahan di Provinsi Bali. ECOTROPHIC: Jurnal Ilmu Lingkungan, 6(1), 1-7.

Central Bureau of Statistics of Badung Regency. (2009). Badung Regency in Figures 2009. Badung, Indonesia: Statistics Badung Regency.

Nuarsa, I. W., As-syakur, A. R., Gunadi, I. G. A., \& Sukewijaya, I. M. (2018). Changes in Gross Primary Production (GPP) over the Past Two Decades Due to Land Use Conversion in a Tourism City. ISPRS International Journal of Geo-Information, $\mathbf{7}(2), 57$.

Vrabel, J. (1996). Multispectral imagery band sharpening study. Photogrammetric engineering and remote sensing, 62(9), 1075-1084.

Yin, Z. Y., Walcott, S., Kaplan, B., Cao, J., Lin, W., Chen, M., Liu, D., \& Ning, Y. (2005). An analysis of the relationship between spatial patterns of water quality and urban development in Shanghai, China. Computers, Environment and Urban Systems, 29(2), 197-221.

Zhi-Yong, Yin. 2006 . An analysis of the relationship between spatial patterns of water quality and urban development in Shanghai, China. Journal www.elsevier.com/locate. (16/01/2013)

(C) 201x by the authors; licensee Udayana University, Indonesia. This article is an open access article distributed under the terms and conditions of the Creative Commons Attribution (CC-BY) license (http://creativecommons.org/licenses/by/4.0/). 